\section{A teoria sociológica contemporânea. Da superdeterminação pela teoria à historicidade}

Paulo César Alves ${ }^{1}$

Resumo: Ao se situar no campo da metateoria, o presente trabalho tem por objetivo discutir uma das principais premissas que está subjacente à sociologia contemporânea: a historicidade. Contrapondo-se à teoria sociológica desenvolvida entre as décadas de 1940 e 1970, as "novas sociologias" têm procurado ultrapassar um pressuposto epistemológico daquele período - a superdeterminação pela teoria. Nesse esforço, têm outorgado à ideia de historicidade uma posição central no entendimento da ação humana. Constituindo-se como aberturas para o futuro (seu componente de "liberdade"), a ação, longe de ser um processo "cego", sempre revela necessariamente tanto o seu enraizamento no mundo social e físico quanto a possibilidade de transcender essa situação.

Palavras-chave: teoria sociológica; sociologia contemporânea; ação social; historicidade; metateoria.

“[...] a possibilidade da história, colocada no ser humano - precisamente a sua liberdade -, não é ela mesma histórica, e sim ontológica; e uma vez descoberta, ela mesma passa a ser o fato central na evidência de onde toda ontologia se alimenta" (Jonas, 2004: 210).

\section{Introdução}

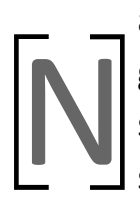

as últimas três décadas, a sociologia - como as ciências sociais em geral - tem desenvolvido uma crescente preocupação em repensar os pressupostos teórico-metodológicos sobre os quais se assenta o seu entendimento científico do mundo. Esse fato pode ser constatado pelo número de autores clássicos que são atualmente objeto de releituras (como Mead, Durkheim, Simmel e, principalmente, Weber); pelas reflexões de caráter epistemológico desenvolvidas pelos cientistas
Recebimento:

08.12.2009

Aprovado:

27.02.2010
1. Professor do Departamento de Sociologia da Universidade Federal da Bahia. E-mail: paulo.c.alves@uol.com.br 
sociais; pela multiplicidade de paradigmas e de referências teórico-metodológicas; pelas tentativas de integração e sínteses teóricas propostas; pela busca de superação de uma série de pares de conceitos clássicos (como subjetivo e objetivo, agente e estrutura, coletivo e individual, macrossociologia e microssociologia) e, principalmente, pela expansão de novos campos de pesquisas que ultrapassam as tradicionais fronteiras disciplinares. As trocas multidisciplinares que realimentam novas problemáticas no campo da sociologia - entre a sociologia e a filosofia, entre a sociologia e a história, a psicologia e a linguística - são tão comuns que às vezes somos tentados a indagar se estamos realmente diante da sociologia ou de uma outra disciplina que está se configurando no cenário intelectual. De uma maneira geral, e guardando as devidas proporções, parece que nos últimos trinta anos o ferver da imaginação sociológica iguala-se com o que foi presenciado na passagem do século XIX para o XX, como a série de debates intelectuais (Methodenstreit) que sacudiram na Alemanha daqueles tempos.

Vivemos um momento singular com o advento das "novas sociologias", termo designado por Corcuff (2001) para se referir a um conjunto de teorias que floresceram a partir da década de 1970, como, entre outras, a sociologia existencial (John Johnson, Joseph Kotarba e Jack Douglas), a teoria do atorrede (Bruno Latour), a teoria da ação criativa (Hans Joas), a sociologia fenomenológica (Jack Katz), além das mais conhecidas e não tão "novas" como a "praxeologia" ou "construtivismo estruturalista" de Pierre Bourdieu, a teoria da estruturação de Anthony Giddens, a etnometodologia de Garfinkel e Aaron Cicourel.

Tendo em vista as transformações atuais que acontecem no campo da sociologia é necessário indagar quais são os princípios que fundamentam os universos conceituais dessas "novas sociologias". Tarefa ousada, sem dúvida, mas importante, pois com essa reflexão podemos traçar as principais linhas de convergência e divergência que imprimem uma identidade na constituição do atual campo sociológico. Assim, teremos condições de aumentar o nível de compreensão das galáxias sociológicas e, através dessa perspectiva globalizante, avaliar mais criticamente os alicerces que sustentam o nosso conhecimento científico do mundo social.

Um dos pontos mais complexos na discussão sobre os pressupostos teórico-metodológicos das "novas sociologias" diz respeito ao fato de que elas assumem diferentes configurações conceituais e desenvolvem problemá- 
ticas distintas entre si. Não se constituem em blocos monolíticos. Contudo, tal característica não invalida a ideia de que elas partilham alguns princípios que podem ser identificados, pelo menos a nível metateórico. O objetivo geral do presente trabalho é contribuir com essa discussão. Mais especificamente, pretende-se apresentar, em breves linhas, uma das grandes premissas que parece estar subjacentes às "novas sociologias": a historicidade.

Antes de prosseguir, é importante ressaltar que a análise aqui desenvolvida situa-se no campo da metateoria. Atualmente objeto de reflexão sistemática por parte de alguns sociólogos (Ritzer, 1981; Brewer \& Hunter, 1988; Noblit \& Hare, 1988; Alexander, 1982), a metateoria pode ser definida como o estudo que procura identificar e caracterizar princípios, valores e instituições sociais que estão subjacentes às estruturas teóricas ou a um dado campo científico. O objetivo principal de uma análise metateórica é obter uma compreensão mais sistemática - tanto a nível cognitivo como institucional - de uma teoria ou um conjunto delas, buscando refletir, no caso das ciências sociais, as questões relacionadas aos fundamentos ou às estruturas intelectuais subjacentes à teoria social e às influências socioculturais na constituição da teoria (como a formação de vínculos ou redes sociais entre teóricos, "escolas" e instituições de ensino e pesquisa).

\section{Um ponto de inflexão na história da sociologia}

Qualquer discussão sobre a "sociologia contemporânea" deve começar por situá-la em um dado tempo. Para os limites do presente artigo, delimitamos, a grosso modo, o seu "início" a partir dos fins da década de 1970. Uma data um tanto arbitrária e com grande variância entre países. Mas, de uma maneira geral, as "novas sociologias" caracterizam-se por (re)expressar um amplo conjunto de recursos teórico-metodológicos que se diferenciam - e, ao mesmo tempo, são desdobramentos - das orientações e correntes que foram hegemônicas no universo acadêmico entre as décadas de 1940 e 1970, principalmente após a Segunda Guerra. Picó (2003) designou esse período de “idade de ouro" da sociologia (cf. também Friedrichs, 2001; Platt, 1996; Hinkle, 1994; Arnove, 1982). Assim, o principal ponto de contraposição desenvolvido pela sociologia contemporânea não é exatamente com o período "clássico" da disciplina, cujos epígenos - Marx, Durkheim, Mead, Simmel e Weber, entre outros constituem atualmente borbulhantes e diversificadas fontes de inspiração.

A sociologia entre as décadas de 1940 e 1970 caracterizou-se por sua maior institucionalização nas universidades, como foi o caso da Inglaterra 
(Lockwood, Ginsberg, Marshall), da França (R. Aron, Gurvitch, Friedmann, Stoetzel) e da Alemanha (König, Adorno). Nos Estados Unidos, a sociologia já tinha assegurado seu nicho acadêmico nos princípios do século XX. Mas só após a Segunda Guerra é que a sociologia americana despontou a nível internacional, "desregionalizando-se" através de seus grandes teóricos ou metodólogos, como Parsons, Merton e Lazarsfeld. Sem dúvida, o pósGuerra foi uma época de maior "popularidade" da sociologia, tanto no mundo acadêmico como fora dele, e de imensa produção de pesquisas, havendo nítido destaque para os estudos quantitativos, principalmente os "surveys". As investigações de Samuel Stouffer (que trabalhou com Parsons, em Havard) e Paul Lazarsfeld (parceiro de Merton, na Columbia) inspiraram muitos sociólogos. É importante lembrar que o crescimento da sociologia no pós-Guerra foi amplamente favorecido pela proliferação dos institutos de opinião pública, pelo apoio das fundações de investigação aplicadas e ajudas de intercâmbios científicos. Ao se desenvolver no contexto do pós-Guerra, a sociologia era vista majoritariamente como uma disciplina cuja tarefa era de reconstruir e modernizar uma sociedade que "renascia" após o conflito de ordem mundial. As fontes de financiamento não eram apenas provenientes do Estado, mas também de fundações particulares, como a Rockfeller, a Carnegie e a Ford. Por exemplo, as relações entre a Unesco e a Associação Internacional de Sociologia (ISA) foram significativas. Como fruto dessa relação, surgiu o Bulletin International des Sciences Sociales, que posteriormente se converteu na Revue Internationale des Sciences Sociales. Foi também pelos auspícios da Unesco que a ISA celebrou o seu primeiro congresso (Oslo, setembro de 1949), nele criando a revista Current Sociology.

Em síntese, entre 1940 e 1970 a sociologia parecia estar assentada sobre bases sólidas. Predominou neste contexto uma preocupação de identificar e defender um paradigma teórico particular que consubstanciasse os princípios básicos da epistemologia sociológica. Embora não fosse consensual, havia por parte de muitos sociólogos um acordo tácito de que os princípios morfológicos básicos sobre os quais assentavam cientificamente o entendimento do mundo social - o grau de generalizações abstratas e universais, tanto a nível conceitual quanto metodológico - já estavam construídos ou parcialmente construídos. Nessa perspectiva, a sociologia estava entrando finalmente nos "eixos", isto é, em processo de rigorosa delimitação do seu campo científico, cuja plena consolidação poderia estabelecer mútuas conexões entre as diferentes orientações teóricas existentes. A sociologia marchava a largos passos para finalmente atingir um estágio tão desejado 
de maior maturidade científica: desvincular-se definitivamente das tradições filosóficas e ideológicas. A vitória do sonho comtiano...

As décadas de 1970 e 1980 interrompem esse sonho. A partir desses anos a sociologia começou apresentar visíveis mudanças tanto no processo de reestruturação dos seus pressupostos epistemológicos quanto em sua institucionalização acadêmica. É claro que essas transformações vão variar de país a país. No caso brasileiro, por exemplo, a década de 1990 foi palco de maiores agitações na imaginação sociológica do que aquela vivenciada nos finais dos anos 1970 nos Estados Unidos e em alguns países europeus. Essas duas décadas constituem um ponto de inflexão para a reconstituição da sociologia não só porque a disciplina, particularmente nos Estados Unidos, sofreu uma "crise de paradigma" ${ }^{2}$ dominante, abrindo-se para novas configurações multiparadigmáticas, mas também porque na Europa, onde haviam se proliferado outros paradigmas, a sociologia se institucionalizou definitivamente ao consolidar um corpo de conhecimento, métodos, técnicas e teorias que passaram a ser referências importantes para a análise da realidade social (Picó, 2003). É a partir dos anos 1970 que muitos dos atuais cientistas sociais europeus passaram a ter reconhecimento internacional, como foi o caso de Giddens, Bourdieu, Ulrich Beck, Zygmunt Bauman, Hans Joas entre muitos outros. O processo de revigoramento das sociologias nacionais gerou uma maior internacionalização da sociologia e, consequentemente, uma redução da americanização da disciplina, até então predominante.

A chamada crise da sociologia dos anos 1970 é um fenômeno complexo, pois abarcou aspectos muitos diferentes do universo intelectual, social e político do mundo ocidental. Embora os estudos sobre esse período se utilizem de diferentes perspectivas interpretativas (Marsal, 1977; Picó, 2003), há um certo consenso de que a "crise" da sociologia desse período foi decorrente de mudanças culturais e de valores desenvolvidos pelos diversos movimentos sociais ocorridos na década de 1960. Muitos desses movimentos assinalavam para uma "revolução cultural" plasmada pelas transformações das condições materiais, de estilos de vida, de liberdades pessoais, explicitando os desajustes entre a estrutura institucional da sociedade civil (como a universidade) e uma educação mais permissiva e democrática. Exemplo significativo é a "revolta estudantil" dos anos 1960 que, para a constituição do campo sociológico, foi uma das mais expressivas, pois, entre outros aspectos, colocou em questão a qualidade do ensino, a estreiteza das estruturas científicas, a deterioração das funções universitárias e o predomínio da sociedade tecnocrática. Nesse contexto, a sociologia foi

2. O termo paradigma tem múltiplos sentidos. Para o presente trabalho, paradigma é utilizado para se referir a um conjunto de ideias, valores, princípios, técnicas e hábitos (e mesmo crenças), compartiIhados pelos membros de uma dada comunidade científica, que são empregados como modelos ou exemplos para o entendimento de uma dada realidade. 
objeto de ataque: pela sua colaboração com os planos reformistas; pela sua identificação com a teoria funcionalista americana; pelo seu "sociologismo" e fechamento às indagações filosóficas; pelo seu caráter nomotético e uni-paradigmático. Além do mais, a nível teórico, os movimentos sociais levantaram questões importantes. Uma delas é referente à história: são os atores sociais que constituem o sujeito da história ou a história é dotada de uma lógica imanente, constituindo um processo sem sujeito?

Mas há também um outro aspecto bastante significativo para melhor compreendermos as transformações ocorridas no seio da sociologia. Um fato importante que pode ser observado após a segunda guerra diz respeito à expansão econômica mundial. Estimulado em grande parte pela guerra fria, esse processo implicou um verdadeiro salto quantitativo nas organizações ligadas à investigação. As grandes potências passaram a investir nas ciências sociais, embora os recursos destinados a essas ciências tenham sido bem menores do que os disponíveis para as "ciências naturais". Como resultado desse processo, houve um crescimento significativo de centros e instituições acadêmicas não apenas nos Estados Unidos e Europa, mas também em outros lugares em que a estruturação institucional das ciências sociais estava até então pouco desenvolvida. Como decorrência da política de investimentos públicos e privados, as grandes potências, principalmente os Estados Unidos, encorajaram, de forma direta ou indireta, o aparecimento de diversas instituições (notadamente acadêmicas) nas quais as ciências sociais ocuparam posição importante. Dois aspectos desse processo têm importância notável para as futuras transformações das ciências sociais. O primeiro diz respeito à expansão quantitativa e geográfica dos sistemas universitários a nível mundial e, a partir dos anos 1960 e 1970, o crescimento da pós-graduação, fato que levou à multiplicação do número de cientistas sociais. Em um contexto de mudanças na distribuição do poder no mundo, os movimentos sociais da década de 1960, a nova afirmação política de povos não europeus e suas motivações políticas subjacentes, tiveram como consequência a proliferação de novas temáticas de estudos, a intromissão recíproca de áreas disciplinares próximas, a redução de uma concepção eurocêntrica das ciências sociais, entre outros aspectos. O segundo refere-se à criação de centros e institutos de ensino e pesquisa que atraíram indivíduos ou grupos de diferentes filiações disciplinares. Assim, historiadores, sociólogos de inclinação nomotética, antropólogos, psicólogos, economistas e outros, passaram a desenvolver um diálogo entre si, mesmo de forma pontual ou temporária (Wallerstein, 1996). Os resultados de todo esses processos foram múltiplos. Um deles, a crescente ênfase na 
multidisciplinaridade que, sob certos aspectos, pôs em causa muitos dos pressupostos vigentes das ciências sociais.

Uma questão importante relacionada ao ponto de inflexão da teoria sociológica nas décadas de 1970 e 1980 diz respeito à natureza das transformações ocorridas no interior das ciências sociais. Grande parte dos estudos relacionados a essa questão tende a considerar que aquelas décadas representaram um momento de ruptura e formação de uma nova etapa da evolução sociológica. Essa tese é defendida por Gouldner (1970) e muitos outros. Para Alexander e Colomy (1990), por exemplo, a teoria sociológica da década de 1980 apresentou uma mudança drástica em relação às velhas e reificadas etiquetas que dominaram as ciências sociais da época dourada. Para eles, a entrada de uma nova geração de sociólogos foi responsável por uma reconfiguração da disciplina, fazendo desaparecer velhas fronteiras e divisões teóricas até então existentes. As ideias de Thomas Kuhn, desenvolvidas no seu livro A estrutura das revoluções científicas (1962), foram amplamente utilizadas por uma plêiade de cientistas sociais para explicar a "crise", a "revolução" e o surgimento de novos "paradigmas" nas ciências sociais. ${ }^{3}$

Considerar que as décadas de 1970 e 1980 representam uma ruptura no sentido kuhntiano com a "idade de ouro" da sociologia é não considerar devidamente alguns aspectos do processo de transformação das ciências sociais. A sociologia que floresce a partir daquele momento não significou necessariamente uma mudança unidirecional ou uniforme das ciências sociais. Tal fato parece consensual nos nossos dias. As mudanças ocorridas assumiram a forma de um aprimoramento contínuo ou de adaptação frente ao quadro disciplinar e paradigmático predominante na "idade de ouro" da sociologia. Afinal, a continuidade da tradição - continuidade tão propriamente humana - não é algo que se deixe facilmente ser contrariado pela insinuação ou interrupção de novos paradigmas interpretativos. As décadas de 1970 e 1980 assinalaram principalmente para a perda de um modelo hegemônico do pensar sociológico, conduzindo para o surgimento de um pluralismo dinâmico no campo dessa disciplina. Isso significa dizer que, por um lado, os paradigmas teóricos que foram hegemônicos na "idade de ouro" da sociologia sobrevivem até os nossos dias, embora com nova "roupagem", com novas problemáticas. Exemplos significativos desse processo seriam a proposta neofuncionalista de Jeffrey Alexander, Paul Colomy e Charles Camic e o "marxismo analítico" de Jon Elster, Ernesto Laclau e Jameson. Por outro lado, novas concepções e construções teóricas que estavam à margem das tendências hegemônicas entre os anos 1940 e 1970 emergi-

3. O trabalho de Robert Friedrichs ("A sociology of sociology"), publicado em 1970, parece ter sido o primeiro de uma série de estudos desenvolvidos a partir de uma perspectiva kuhniana (Friedrichs, 2001). Dentro dessa perspectiva, cabe lembrar os trabalhos de Derek Phillips (1973), Tom Bottomore (1975) e George Ritzer (1975). 
ram, assumindo posição de destaque no universo sociológico. O interacionismo simbólico é um exemplo. Essa teoria só começa a adquirir um status significativo no panteão internacional da sociologia nos fins dos anos 1960, com a publicação do livro de Blumer - Symbolic interacionism (1969). Lembremos, entretanto, que Herbert Blumer completou seu doutorado em 1928 e iniciou a publicação das suas ideias em 1933, através de dois livros, Movies and conduct e Movies, deliquency and crime. Um outro exemplo é o pragmatismo. Pensadores como Pearce, Mead e Dewey, fonte de referências de muitos cientistas sociais atuais (como Hans Joas), praticamente ficaram alijados entre os anos 1940 e 1970. Fato um tanto semelhante acontece com as sociologias de origem fenomenológica. As principais obras de Alfred Schutz, fenomenólogo austríaco falecido nos Estados Unidos em 1959, só adquiriram grande sucesso quando foram republicadas entre 1973 e 1976 (os Collect papers I, II e III).

\section{Superando a superdeterminação pela teoria}

Que pressuposições epistemológicas a nova imaginação sociológica tem colocado para assegurar seu conhecimento científico do mundo social? São muitas as respostas para essa questão. Uma delas diz respeito aos esforços que as chamadas "novas sociologias" têm desenvolvido para superação do que poderia se chamar de "superdeterminação pela teoria", perspectiva que caracterizou boa parte do pensamento sociológico dos "anos dourados".

Em 1983, Arthur Stinchcombe proferiu uma palestra na Thomas and Znaniecki Memorial Conference on Social Theory. Nela, Stinchcombe considerou que a sociologia estava divorciada do mundo real. Nas suas palavras, "quanto maior o prestígio de um trabalho sociológico, menos as pessoas suam, riem, são feias ou bonitas (...) as teorias que mais estão divorciadas do sangue, suor e lágrimas são as que têm mais prestígio" (apud Ritzer, 1990: 1). Em certa medida, a fala de Stinchcombe resume o significado da "superdeterminação pela teoria" e aponta para novas perspectivas teóricas.

Um ponto de partida da sociologia que predominou nos "anos dourados" pode ser brevemente resumido nos itens seguintes. Para que o conhecimento científico seja objetivo, é necessário que apreenda uma realidade que subsista "nela mesma", que seja válida para todos. O que se espera do conhecimento sociológico é que ele possa apreender regularidades (estruturas, sistemas de relações) independentemente das vontades ou consciências individuais. A possibilidade de se obter um conhecimento correto 
do mundo social deveria estar embasada em alguns pressupostos teóricometodológicos, sendo que dois deles são de grande importância. O primeiro diz respeito à ciência, que deve ser essencialmente analítica e abstrata, o que significa dizer que ela constrói a realidade por meio de símbolos conceituais que não devem ser confundidos com a "realidade concreta". Esse postulado - tão caro a Parsons - foi resumido por Whitehead (2006) ao observar que, para essa perspectiva metodológica e epistemológica, os elementos de um todo - do qual são isolados através de uma análise - não podem ser igualados às ocorrências concretas. Assim, os símbolos conceituais são elaborados ao selecionarmos na realidade certos traços, certos elementos que se tornam privilegiados para estruturar nossa percepção e conhecimento das coisas. Portanto, não se deve exigir do conhecimento uma adequação perfeita entre a realidade objetiva e a estrutura conceitual. A teoria é constituída por um sistema integrado que possui uma estrutura lógica determinada, ou seja, o seu quadro de referência é uma coleção sistematizada de proposições relativas a domínios conexos - mas diferenciados - entre as quais a teoria estabelece (com "precisão objetiva") uma série de equivalências e diferenças. Assim, embora abstrata, a teoria não é arbitrária. Ela é objetiva no sentido que procura dar respostas a questões relevantes estabelecidas pelos problemas construídos pelo observador. Por outro lado, toda teoria tem de ser precisa no sentido em que é inseparável da verificação.

O segundo pressuposto é o de que, para ser de algum modo significativo, um conceito científico deve estar em condições de relacionar-se à experiência, o que será o teste de sua verdade. Assim, a significação de um conceito só pode ser concebida nos termos das experiências que o teste possibilita. Nessa perspectiva, para que o conceito possa atender a esse pré-requisito - tenha sólida base científica - é necessário que ele seja submetido a operações lógicas relativas aos objetos da experiência. $O$ conceito deve, portanto, ser "operacionalizado". Conhecer essas operações é compreender o conceito tão amplamente quanto requer a ciência.

Dessa forma, o operacionismo fornece não apenas um critério de significação, mas um meio de descobrir ou de enunciar qual o significado de um conceito particular: basta que especifiquemos as operações que governam sua aplicação (Kaplan, 1975: 43).

A tese que está subjacente a esses dois pressupostos epistemológicos e metodológicos é a de que a abstração é o recurso explicativo último dos fenômenos sociais. Embora fosse considerada como um conhecimento em- 
pírico, a sociologia pretendia se situar distante de qualquer noção derivada imediatamente da percepção. Assim, embora parta de casos particulares, empíricos, para explicá-los a sociologia deveria se mover para o âmbito da completa abstração. De nítido sabor kantiano, a tese fundamental é de que qualquer que seja o objeto de análise sociológica, para que ela seja científica é necessário tratar os fenômenos sociais, os acontecimentos mundanos, a partir de um ponto colocado fora desses fenômenos, isto é, no plano cognitivo, no plano conceitual. Em outras palavras, um princípio fundamental do conhecimento proposto pelas ciências sociais - que, aliás, caracteriza toda a ciência moderna desde o século XVII - é o de que a compreensão da realidade última de um fato social depende de configurações teórico-metodológicas.

Assim, como observa Whitehead (2006), um elemento fundamental da ideia de ciência está na conviç̧ão da existência de uma "ordem das coisas" ou "senso de ordem" (Whitehead, 2006:16), como se o mundo fosse dotado de um "enredo" próprio. Todas as coisas são exemplificações de princípios gerais que reinam em toda a ordem natural. Apreendemos cientificamente algo quando o colocamos em uma "ordem das coisas" ou "senso de ordem". A atenção é voltada, portanto, para configurações conceituais ou modelos analíticos, para princípios cognitivos que guiam o conhecimento. Não é por acaso que a matemática, com seus artifícios lógicos, obteve um status proeminente na era dourada da sociologia. Foi nessa época que o survey foi praticamente tomado como exemplo de procedimento correto, científico. A moderna matemática - libertando "o homem dos grilhões da experiência terrestre", no dizer de Hanna Arendt (2000: 277) - criou uma linguagem que reduz os dados sensoriais e as ações humanas a símbolos e, com isso, permite "medir" acontecimentos por uma ordem matemática, desde que os conceitos sejam devidamente operacionalizados. A matemática transforma a multiplicidade das coisas, por mais desordenada, incoerente e confusa que seja, em certos padrões e configurações. Nessa perspectiva, como observa Bruno Latour (2005), o termo "social" designa um status estabilizado de acontecimentos, um conjunto de laços que, mais tarde, pode ser mobilizado para explicar outros fenômenos. É uma força específica que explica a durabilidade das relações humanas. Ou seja, o social é feito de algo (força, poder ou capacidade) perdurável.

Há no pressuposto da abstração como recurso explicativo dos fenômenos sociais uma pretensão racionalista que penetra no pensamento científico. Nessa perspectiva, como já observamos, expomos os fenômenos sociais a configurações e fórmulas elaboradas pela mente, a construções teórico- 
metodológicas que estão além do alcance da experiência. Mas, cabe perguntar, ao nos determos nas estruturas mentais, não corremos o risco de perder o mundo?

Como Hannah Arendt observa acertadamente,

quanto maior a distância entre o homem e o seu ambiente, o mundo ou a terra, mais ele pode observar e medir, e menos espaço mundano e terreno lhe restará (2000: 263).

Ou seja, quanto mais nos desvencilhamos do que está perto de nós e nos retiramos a uma distância do que nos rodeia, terminamos nos alienando do nosso ambiente imediato e terreno e, assim, "perdemos o mundo". Ao centrar a reflexão sociológica na busca de regularidades objetivas (estruturas, leis, sistemas de relações etc.), corremos o risco de perder de vista a pluralidade humana, as distinções, diferenças e alteridades que marcam as ações humanas e os mundos sociais. Parece-me justamente que essa preocupação - a de não "perder o mundo" - é central para as "novas sociologias".

A pluralidade humana - essa paradoxal pluralidade de seres singulares - é a condição básica da ação e do discurso. Como diz Hannah Arendt,

[...] se não fossem diferentes, se cada ser humano não diferisse de todos os que existiram, existem ou virão a existir, os homens não precisariam do discurso ou da ação para se fazerem entender. Com simples sinais e sons, poderiam comunicar suas necessidades imediatas e idênticas (2000: 188).

Em suma, preocupado em buscar regularidades nos fenômenos humanos, a sociologia da "idade do ouro" perdeu do seu campo de vista justamente uma condição essencial do mundo humano: sua historicidade, uma das mais decisivas experiências humanas.

Se existe algum ponto de convergência nas sociologias contemporâneas é a noção de que a realidade social é essencialmente dotada de historicidade. Embora de formas distintas, todas as chamadas "novas sociologias" lidam com questões da historicidade e, com isso, privilegiam em suas análises a temática da ação. Neste sentido, o ponto de partida destas abordagens diz respeito ao fato de que é propriedade humana a faculdade de agir, de iniciar processos novos e sem precedentes (embora necessariamente assen- 
tados em "contextos" preexistentes), cujo resultado é incerto e imprevisível. A historicidade é a condição ontológica do ser humano e a sua descoberta é um fato central de onde toda a teoria social se alimenta.

É importante não confundir historicidade com história e tampouco com historicismo. A historicidade é prévia à noção de história. É a possibilidade de construir a história. Em outras palavras, a historicidade não é resultado da história, mas esta é resultado daquela. Por sua vez, o historicismo é um conjunto de doutrinas que enfatizam o papel desempenhado pelo caráter histórico do homem. O conceito de historicidade tem um outro sentido: refere-se à ideia de que todo o ser humano está regido pela temporalidade. A temporalidade é a condição de possibilidade da historicidade, é um modo pelo qual o ser humano tem de assumir seu próprio futuro.

A noção de historicidade pressuposta na teoria sociológica contemporânea possui três importantes aspectos: $a$. lida com construções passadas (a ideia de que o mundo social se constrói a partir das condições diretamente dadas e herdadas do passado); $b$. estas construções são atualizadas nas práticas e nas interações da vida cotidiana dos atores (as formas sociais passadas são apropriadas, reproduzidas e transformadas enquanto outras são inventadas); c. constitui aberturas de campos de possibilidades no futuro (a herança passada e o trabalho cotidiano sempre abrem perspectivas para o futuro). Assim, o conceito de historicidade apresenta, simultaneamente, aspectos de "objetivações" e "interiorizações" da realidade social. Se por um lado, remete a mundos objetivados (os indivíduos e os grupos se servem de palavras, objetos, coisas, regras, instituições etc. legados pelas gerações anteriores, transformando-os e criando novas formas) por outro, se inscreve em mundos subjetivos e interiorizados (construídos de formas de sensibilidade, de percepção, de conhecimento).

A centralidade da historicidade assumida pela teoria sociológica contemporânea tem, inegavelmente, implicações teórico-metodológicas. Destaquemos apenas duas. Em primeiro lugar, é importante levar em consideração que toda ação (fundamento da historicidade) atua sobre um meio no qual toda reação se converte em reação em cadeia (todo processo é causa de novos processos). Como a ação atua sobre seres que também são capazes de agir, a reação (além de ser uma resposta) é sempre uma nova ação com poder de atingir ou afetar os outros. Nesse aspecto, o ator nunca é simples "agente", mas também, ao mesmo tempo, paciente. Termos tão caros à teoria contemporânea, como "reflexividade" (Giddens), "redes" (La- 
tour), "mundo-de-vida" (Habermas, entre outros), revelam de forma direta ou indireta como as ações sempre estabelecem relações, havendo nesse processo uma tendência inerente de violar limites e transpor fronteiras. Afinal, como chama atenção Hannah Arendt (2000), toda ação humana, por não se restringir a um círculo fechado, tem a característica de ser ilimitada. O caráter ilimitado da ação é devido a produtividade específica da ação em estabelecer relações. Tendo em vista a sua especificidade em estabelecer campos de possibilidades no futuro, toda ação tem um caráter de imprevisibilidade. Ou seja, embora sempre existam certas proteções para conter a tendência inerente da ação em violar os limites, o resultado da ação é imprevisível. O pleno significado da ação somente se revela quando ela termina. A luz que ilumina os processos de ação - portanto, de todos os processos históricos - só aparece quando eles terminam.

Em segundo lugar, é fundamental salientar que falar de "liberdade" da ação as perspectivas para o futuro abertas pela ação humana - não significa admitir que o dinamismo humano é um processo "cego"; algo que pode ser reduzido às meras acumulações de resultados aleatório que se sedimentam ao longo da história. A condição básica do privilégio da "liberdade" da ação consiste no fato paradoxal de que nunca há despreendimento da integração geral das ações no todo social e material. É justamente essa integração, esse laço que une a atividade humana ao seu mundo (espiritual, físico e biológico), que é indispensável para que a ação possa "transcender", ultrapassar parte daquilo que mantém a relação. A ação evidencia sem cessar a vertigem da liberdade: a polaridade de ser e não ser enraizada. $E$ a tarefa que a sociologia contemporânea se impôs foi a de tentar determinar o caráter de liberdade humana na relação com o mundo social, ou mesmo com a natureza.

\section{Conclusão}

Uma característica essencial das ciências sociais contemporânea é que os seus estudiosos estão cada vez mais conscientes das mudanças importantes que têm atualmente ocorrido na teoria social. Nos últimos trinta anos, os sociólogos têm cada vez mais refletido sobre os pressupostos teóricos que prevaleceram após a Segunda Guerra. Como chamamos a atenção, os cientistas sociais do pós-guerra tiveram uma nítida preocupação em estabelecer padrões de verificabilidade e construir teorias de corte hipotéticodedutivo como condições que garantiriam o caráter de cientificidade das suas disciplinas. Tais preocupações resultaram na constituição de um saber científico cuja legitimidade seria outorgada pela "operacionalização" dos con- 
ceitos e das formulações de leis e "generalizações" atemporais. Assim, não havia muito espaço para as questões da interpretação ou da compreensão de significados (Verstehen). Essa situação sofre mudanças substanciais a partir das décadas de 1970 e 1980. Com o relativo declínio do funcionalismo nos Estados Unidos e do estruturalismo na Europa, aparecem ou emergem orientações teóricas novas ou parcialmente excluídas do panteão acadêmico. Digno de nota é a preocupação que os teóricos passam a ter pela integração das dicotomias estabelecidas nas ciências sociais. Há um renovado retorno aos seus clássicos, novas propostas de sínteses teóricas são formuladas e, inevitavelmente, ressurge a preocupação com a metateorização, isto é, pelo questionamento das estruturas subjacentes à teoria. $\mathrm{O}$ movimento autoreflexivo, que os cientistas sociais passam a demonstrar, fez com que houvesse um retorno à filosofia. Autores mais alinhados com a filosofia do que propriamente com a sociologia - como Schutz, Merleau-Ponty, Paul Ricoeur, Michel Serres, Foucault, Habermas, Charles Taylor e Castoriadis - fazem usualmente parte nos programas das disciplinas sociológicas. Por outro lado, cientistas como Bourdieu, Giddens, Luhmann, Jeffrey Alexander escrevem artigos de caráter eminentemente filosófico. Nesse contexto, a teoria da ação social recebe novo impulso, resultando na expansão do campo conceitual das ciências sociais e, com isso, inaugurando novas problemáticas.

No presente trabalho, procuramos refletir sobre dois pontos. O primeiro refere-se ao processo de transformação da sociologia iniciado nas décadas de 1970 e 1980. Observamos que as ciências sociais (e com elas, a sociologia) perderam a relativa uniformidade disciplinar. Mais especificamente, houve uma diminuição do nível de consenso em torno das linhas de demarcação entre as ciências, sem que com isso tenha se eliminado a disciplinarização. A sociologia tem cada vez mais assumido um caráter multidisciplinar. Como resultado desse processo - e aí talvez esteja a grande novidade das ciências sociais contemporâneas - é o estabelecimento da reconciliação e novas alianças entre posições até então tidas como antinômicas entre ciências da natureza, ciências humanas e filosofia. As novas configurações que emergem das pesquisas em curso são usualmente atravessadas por polaridades múltiplas

A segunda questão diz respeito às diversas tentativas de superação a superdeterminação pela teoria. As novas interrogações sobre o vínculo social - como as questões relacionadas à historicidade e a ação - implicam uma outra escala de análise, mais próxima dos atores sociais. Os estudos voltados para a compreensão do cotidiano têm o papel de alavancar metodolo- 
gias mais sensíveis à percepção do instituinte do que do instituído. A análise sociológica tem gradativamente reformulado dois modelos interpretativos que foram dominantes: aqueles que privilegiam o indivíduo e suas capacidades estratégicas ou táticas e, por outro lado, o modelo oposto no qual predominava os esquemas de reprodução, a lógica interna de instituições manipuladoras e redutivas. Neste sentido, o sujeito que emerge das sociologias contemporâneas não é divinizado e tampouco dissolvido. Mais do que nunca, a sociologia cada vez mais leva em devida consideração a complexidade crescente dos problemas e recusa qualquer forma de dogmatismo ou de reducionismo, passando a lidar mais proximamente com os grilhões da experiência terrestre. Com isso reconhece a impossibilidade e inutilidade de encerrar o ser humano numa lógica exclusivista, quer seja moral, cultural, física ou genética.

Abstract: Situated in the field of metatheory, the present paper aims to discuss one of the main premisses underlying contemporary sociology: the idea of historicity. As opposed to the sociological theory produced being the 1940s and 1970s, the new sociologies have sought to overcome the dominant epistemological premise of that period - overdeterminantion by theory. In their effort, they have granted the idea of historicity a central role in the understanding of human action. Action is not a blind process: as an opening to the future (component of liberty), it reveals both its grounding on the social and physical situation and its possibility of transcending that situation.

Key words: sociological theory; contemporary sociology; social action; historicity; metatheory.

\section{Referências}

Arendt, H. (2000) A condição humana. Rio de Janeiro: Forense Universitário.

AleXAnder, J. C. (1982) Theoretical logic in sociology. Positivism, presuppositions, and current controversies. Berkeley: University of California Press.

Alexander, J. \& Colomy, P. (1990) “Neofinctionalism: reconstructing a theoretical tradition", in G. Ritzer (ed), Frontiers of social theory: the new syntheses. Nova York: Columbia University Press: 33-67.

Arnove, R. F. (1982) Philanthropy and cultural imperialism. Bloomington: Indiana University Press. 
Bottomore, T. (1975) "Competing paradigms in macrosociology", in A. Inkless, J. Coleman, M. Smelser (eds), Annual Review of Sociology. Palo Alto: Annual Reviews Inc.: p. 191-203.

Brewer, J. \& Hunter, A. (1989) Multimethod research: A synthesis of styles. Newbury Park: Sage.

Corcuff, P. (2001) As novas sociologias. Construções da realidade social. Bauru: Edusc.

FrIedRICHS, R. (2001) Sociología de la sociología. Buenos Aires: Amorrortu.

Gouldner, A. W. (1970) The coming crisis of western sociology. Nova York: Basic Books.

HINKLE, R. C. (1974) Developments in american sociological theory, 1915-1950. Nova York: State University of New York.

Jonas, H. (2004) O princípio vida. Fundamentos para uma biologia filosófica. Petrópolis: Vozes.

Kaplan, A. (1975) A conduta na pesquisa. São Paulo: Edusp.

Latour, B. (2005) Reassembling the social. An introduction to actor-network theory. Oxford: Oxford University Press.

MARSAL, J. F. (1977) La crisis de la sociología norteamericana. Barcelona: Península.

Noblit, G. W. \& HARE, R. D. (1988) Meta-ethnography: Synthesizing qualitative studies. Newbury Park: Sage.

PHILLIPS, D. (1974) "Paradigms, falsifications and sociology". Acta Sociológica, Vol. V: 359-425.

Pıcó, J. (2003) Los años dorados de la sociologia (1945-1975). Madri: Alianza Editorial.

PlatT, J. (1996) A history of sociological research methods in America 19201960. Cambridge: Cambridge University Press. 
Ritzer, G. (1975) Sociology. A multiple paradigm science. Boston: Allyn and Bacon.

- (1981) Toward an integrated sociological paradigm: the search for an exemplar and an image of the subject matter. Boston: Allyn and Bacon.

- - - (1990) "The current status of sociological theory. The new syntheses", in idem (ed), Frontiers of social theory. The new syntheses. Nova York: Columbia University Press: 1-30.

——— . (1993) Teoría sociológica contemporanea. Madri: McGraw-Hill.

Wallerstein, I. (1996) Para abrir as ciências sociais. São Paulo: Cortez.

Whitehead, A. N. (2006) A ciência e o mundo moderno. São Paulo: Paulus. 